\title{
От реальности к виртуальному миру и обратно: как язык помог нам в освоении Интернета и что произошло потом (на материале русского и польского языков)
}

\author{
From the real world to the virtual one and back again: \\ How language had helped us to become familiar \\ with the Internet and what happened after that \\ (based on the Russian and the Polish languages)
}

\begin{abstract}
The paper deals with the linguistic means that had helped us to adapt to virtual reality and that now seem to us to have existed always. The words and expressions didn't appear out of nowhere - they were imported from our everyday language where they had been used for naming objects and processes in the real world. Thus the new realm, such as the physical one, was marked by language signs that determine the nature and the structure of our conception of the Internet which is interpreted generally as a physical space (different types of the latter). These signs are described here in terms of conceptual metaphor theory. Recently we have been dealing with some new, "web-born" expressions. It is shown that such expressions are no more limited to the describing of the Internet and are extended to the real world; it can be said they provide us with new tools to interpret the "old" reality. Thereby we can see the very moment when the source and the target domains (that is real and virtual worlds) are switching their places.
\end{abstract}

Keywords: conceptual metaphor, Internet, the Polish language, the Russian language, source and target domains

Ekaterina Starodvorskaia, Uniwersytet im. Adama Mickiewicza w Poznaniu, Poznań - Polska, Irkucki Uniwersytet Państwowy, Irkuck - Rosja, starodvor@gmail.com, ORCID ID: https://orcid. org/0000-0001-6323-2376

В 2020 году сложно себе представить, что когда-то того, что мы называем Интернетом, не было. В конце 90-х гг. (начальный период широкого распространения Интернета) он представлял собой абсолютно новую реальность, в которой пользователям необходимо было научиться существовать. Процесс освоения этой новой реальности (как и любого нового для челове- 
ка фрагмента действительности) требовал, в частности, умения назвать то, с чем мы взаимодействуем, и то, как мы это делаем.

Человечество в целом и каждый отдельный человек в частности, разумеется, не в первый раз столкнулись с необходимостью освоить новую реальность или ее фрагмент. Если отмотать пленку еще на век назад и посмотреть на эпоху начала широкого распространения автомобильного транспорта, то мы увидим, что существенное количество языковых единиц, используемых для наименования транспортных средств, их частей и характеристик, раньше относились к уже освоенному человеком пространству, ср. - экипаж 'рессорная повозка для пассажиров ${ }^{1}$ (перемещаемая лошадьми)' > 'автомобиль' (самодвижущийся):

Провалился в уличную яму извозчик с экипажем и лошадью („Утро России”, 1910)².

Вскоре в Петербурге прибывают 150 заграничных автомобилей [...] плата за пользование таким экипажем будет взиматься без предварительного торга по таксометру („Петербургская газета", 1910).

- кузов 'короб, лукошко из лыка или бересты' > 'часть повозки, экипажа и т. п., служащая для размещения людей или грузов’ > 'в том числе автомобиля':

Англинское изобрђтеніе, по которому маленькой кузовъ навЊшенъ надъ двумя высокими колесами, равно какъ и другое, по которому сиденье поставлено надъ передними колесами, кажется, не нашли еще подражателей (O экипажахъ, 1795).

Снизу кузова и в деталях подвески есть немало открытых полостей, щелей и других „Узкостей” („Советы бывалых”. За рулем, 15.05.2003).

- pаботать 'приводить что-л. в действие, управлять, действовать чем-л. (инструментом, орудием)' > 'находиться в действии, действовать (о механизмах, агрегатах, устройствах и т. п.)' > 'издавать характерные звуки': $p a-$ ботать лопатой - мотор работает исправно - я усльшал, как заработали моторы. Список примеров можно, разумеется, продолжить (ср. колесо, лобовое стекло и пр.).

Мы наблюдаем довольно очевидную и давно описанную тенденцию: человек объясняет себе новое через освоенное, непонятное через понятное, сложное через простое (или то, что кажется простым), абстрактное через конкретное.

1 Значения лексических единиц формулируются, если не указано иное, с опорой на (Evgen'eva).

2 Здесь и далее, если не указано иное, примеры из Национального корпуса русского языка (Nacional'nyj korpus russkogo âzyka). 
Как пишет Стивен Пинкер, признавая огромную объяснительную силу теории концептуальной метафоры (пусть и критикуя ее в некоторых аспектах), „[...] it's jarring to discover that even the airiest of our ideas are expressed («pressed out») in thumpingly concrete metaphors ([...] довольно неприятно осознавать, что даже самые возвышенные из наших мыслей выражаются («выдавливаются») сугубо конкретными, осязаемыми метафорами ${ }^{3 \prime}$ (Pinker 237).

Как эта тенденция выглядит применительно к освоению Интернета? Рассмотрим историю семантического развития слова страница - в обратном хронологическом порядке. Новейшее значение этого слова ('доступный для просмотра пользователем документ в информационной сети, содержащий текст, графические и видеоизображения, звуковое сопровождение со ссылками на информацию других страниц и почтовых ящиков' - Sklârevskaâ 613) является, разумеется, производным от значения 'одна сторона листа бумаги (в книге, тетради)', которое, в свою очередь, восходит к цсл. страна в значении 'одна из боковых поверхностей предмета: бок, край', развившемуся от исходного 'пространство, расположенное в определенном направлении от центра или иной точки отсчета, а также само это направление' (Slovar' russkogo âzyka XI-XVII vv. 126), ср. примеры:

\section{обновить страницу <}

загнуть уголок страницы <

И еже глаголют, пол рыбы снедена, другую же страну и ныне в живых видим (Slovar' russkogo âzyka XI-XVII vv. 127) <

Труп же его [Харитона] скочи на ноги свои и начат трястися на все страны... (Slovar' russkogo âzyka XI-XVII vv. 126).

Идентичным образом выглядит семантическая история польской единицы strona: 'kierunek' > 'każda z powierzchni ograniczających jakąś bryłę, bok, brzeg, ściana, krawędź czegoś, przestrzeń, miejsce na krawędzi czegoś’ (Boryś 581) > 'każda z dwu powierzchni karty papieru; stronica' > 'umieszczone w Internecie pod jednym adresem informacje w postaci tekstu, obrazu lub dźwięku; witryna' (Dubisz). Обратим внимание, что и в русском, и в польском языке сочетаемость новой лексемы очевидным образом свидетельствует о специфических качествах того пространства, в котором находится обозначаемый

\footnotetext{
3 Здесь и далее, если не указано иное, перевод наш.

${ }^{4}$ На вопрос о том, какое из этих значений является исходным (и в древнепольском, и в церковнославянском языке), возможны, очевидным образом, разные ответы. Имея в виду, что значение, связанное с направлением, фиксируется уже в Остромировом Евангелии, мы отмечаем его в качестве исходного, но отдаем себе отчет в более высокой степени конкретности значения, отсылающего к поверхности предмета.
} 
объект: в реальном мире невозможно обновить страницу книги (или odświeżyć stronę).

Итак, логика развития значений в рассмотренном случае выглядит следующим образом: физическое пространство по отношению к точке отсчета (которой является человек или то, что с ним связано) > локализованное физическое пространство (часть рыбы, как в примере выше) > пространство, связанное с конкретной технологией (особенностями переплетения книг) $>$ виртуальное пространство. Следует отметить, что слово пространство, которое мы выбрали для обозначения интернет-среды, представляется нам наиболее универсальным. Способ концептуализации последней может быть, разумеется, разным, ср. замечание Александра Токара:

Indeed, given the complexity and the multi-functionality of the global computer network - as is well-known, the Internet is used in a variety of ways, e.g., for communication, commerce, entertainment, etc. - it is not surprising that in addition to being a series of tubes and a rubbish heap, the Internet is also often referred to as agora, electronic frontier, cyberspace, global village, empyrean realm, information superhighway, ocean of information, container, prosthesis for the senses or limbs, city, etc. (Tokar 1).

Очевидно, однако, что в каждом из случаев отправной точкой для осмысления виртуальной действительности становится некоторый участок физического мира (более или менее конкретизированный - но в любом случае более конкретный, чем тот, который необходимо осмыслить и освоить).

Еще раз подчеркнем, что Интернет как новое явление и новое пространство должен был быть освоен пользователями не только в рамках непосредственного взаимодействия с виртуальными сущностями, но и на уровне их номинации: „[...] при помощи слова человек может как бы «застолбить» обследованную часть окружающей действительности, сказать себе: «Это я уже знаю», повесить табличку-название и отправиться дальше” (Norman 78).

То, что не названо, не существует в актуальном сознании - впрочем, верно и обратное: то, что не важно для человека, не получает собственного, известного подавляющему большинству носителей языка названия (ср. отсутствие в русском языке однословных номинаций для места между носом и ртом, места между пальцами). Новый, виртуальный мир только тогда рождается окончательно, когда он, его составляющие, связанные с ним процессы поименованы. Создание мира во множестве мифологических, религиозных и культурных традиций связано с наделением предметов именами (вспомним об Адаме, дающем имена животным).

Адекватная система названий, следовательно, является условием освоения нового опыта; очевидно, что способ и направление осмысления того, что еще неизвестно человеку, опирается на уже имеющиеся у него представ- 
ления. Освоение виртуального пространства в терминах пространства физического - тенденция, которая реализовывалась и в сфере имен нарицательных, и в сфере имен собственных. Вышеописанную логику демонстрирует название инструмента, при помощи которого осуществляется просмотр интернет-страниц, ср англ. browser, заимствованное русским языком (,a computer program for accessing sites or information on a network (as the World Wide Web)”) и образованное от глагола browse (1. „to feed on browse”; 2. „to read or look over something in a casual way"), исходно связанного с перемещением в физическом пространстве (The Merriam-Webster Dictionary 90).

Подобным образом сконструированы имена собственные - названия первых браузеров на интернет-рынке: уже забытого Netscape Navigator и еще функционирующего, но давно утратившего популярность продукта Microsoft Internet Explorer, cp.:

navigate: 'перемещаться по воде' > 'перемещаться посредством управления транспортным средством' > 'перемещаться';

explore: ‘изучать, исследовать, открывать’; ‘путешествовать с целью приключений или совершения открытий'.

Итак, в большом количестве случаев носители языка осмыслили Интернет и его устройство по образцу структуры физического пространства, доступного нам в непосредственных ощущениях. Теория концептуальной метафоры, предполагающая отношение к последней как к средству познания действительности, как к инструменту организации опыта человека, структурирования его знаний о мире, разумеется, неоднократно служила орудием описания новых единиц, называющих объекты и процессы, связанные с Интернетом (см. Dytman-Stasieńko, Stasieńko; Greiffenstern; Tokar):

Internet i technologia IT $\mathrm{w}$ wymiarze komunikacyjnym jeszcze do niedawna stanowiły obszar nowy i dlatego wymagający oswojenia, również za pośrednictwem znanych terminów i wyobrażeń, stąd zasymilowane już, a często nieidentyfikowane jako metaforyczne określenia [...] np. ikona, pulpit, okno, strona (Dytman-Stasieńko, Stasieńko 12).

Вероятно, если бы классическая работа Джоржда Лакоффа и Марка Джонсона Metaphors We Live by была написана на 15 лет позже, в ней непременно нашлось бы место для описания еще одной концептуальной метафоры, предполагающей в качестве области-источника (source domain) физическое пространство (и его отдельные сферы и варианты существования), опыт восприятия которого способствует структуризации и освоению виртуальной реальности: 
$[\ldots]$ what we are claiming about grounding is that we typically conceptualize the nonphysical in terms of the physical - that is, we conceptualize the less clearly delineated in terms of the more clearly delineated (Lakoff, Johnson 59).

Можно ли утверждать, что в современных европейских языках функционирует концептуальная метафора ИНТЕРНЕТ - ЭТО ФИЗИЧЕСКОЕ ПРОСТРАНСТВО? Вероятно, да, хотя, разумеется, тот конкретный участок опыта, который метафорически проецируется на новую область, может быть описан с большей степенью конкретности: так, Интернет может концептуализироваться как сеть, источник информации (книга), пространство, наполненное жидкостью, рынок и пр. (см. подробнее Greiffenstern 160-163). Очевидно, что в качестве переходной, опосредующей физический опыт человека ступени могут выступать более частные и специализированные области-источники, уже вошедшие в жизнь человека и освоенные в языковом аспекте, например, фотография (польск. przegladarka 'program komputerowy służący do wyszukiwania i przeglądania danych określonego typu, zwłaszcza udostępnianych w rozległych sieciach komputerowych' < 'urządzenie optyczne służące do oglądania przezroczy fotograficznych' - Dubisz ${ }^{5}$ ), книгопечатание (страница), механизмы и устройства (интернет работает/не работает), жизнеобеспечивающие коммуникации (отключить интернет) и пр.

После того как при помощи имеющихся у носителя языка инструментов новое пространство освоено (а точнее, создано), в рамках его языкового измерения начинают развиваться собственные, специфические тенденции, оно начинает существовать в соответствии с закономерностями, родившимися внутри него. Опишем эти закономерности в общем виде.

Одна из них связана с выдвижением на первый план „цифровых” значений слов, уже существующих в языке. Те смыслы, которые служили основой концептуализации виртуального мира, становятся менее актуальными для носителей языка, чем новые, порожденные в пространстве существования информационных технологий, уступают этим новым значениям в частотности реализации. Огромное количество единиц, исходно связанных с физическим пространством в качестве области-источника, для современного носителя языка ассоциируются в первую очередь с виртуальной реальностью, ср. pус. достуn 'возможность обратиться к информации, размещенной в сети' (это значение, не представленное в современных авторитетных толковых словарях русского языка, вероятно, опирается не непосредственно на исход-

5 Здесь, как и в большом количестве других случаев, можно усмотреть влияние структуры английского эквивалента (browser), однако выбор уже существующего в языке экспонента по меньшей мере свидетельствует о том, что новый смысл мог вполне органично встроиться в систему значений польского слова. 
ное пространственное, но идея пути, который необходимо преодолеть в виртуальном пространстве, чтобы воспользоваться некоторой информацией, была одной из базовых в процессе формирования „цифрового” значения, ср. достуn по ссылке), польск. załacznik 'структурная часть электронного письма, содержащая пересылаемые файлы', которое за пределами официальной коммуникации, как кажется, используется прежде всего для обозначения сетевых манипуляций.

Показателен пример русского глагола скачать, который в современном языке крайне редко реализует значение 'выкачивая, удалить откуда-л. что-л. жидкое, поверхностный слой жидкости и т. д.' (отметим, что это дефиниция из словаря под ред. Анастасии П. Евгеньевой, издававшегося в 1981-1984 гг.; в современных авторитетных толковых словарях русского языка названный глагол отсутствует в принципе). Единичные примеры вроде Также организм может скачать воду и с поверхности кожи; Но для этого надо пару раз скачать воду (а потом пользоваться насосом для снабжения своих потребностей во влаге) ${ }^{6}$ не меняют общей картины: глагол скачать используется преимущественно в значении 'сохранить файл из сети на жесткий диск'.

Отметим, кроме того, постепенный отказ от тех метафорических средств, которые, очевидно, перестали адекватно описывать постоянно развивающееся и видоизменяющееся виртуальное пространство, хотя еще совсем недавно были вполне частотными. С распространением широкополосного интернета и беспроводной связи связано, как нам представляется, снижение употребительности словосочетаний войти в интернет и выйти в интернет - особенно первого из них, которое концептуализирует виртуальное пространство как замкнутое и требующее специальных усилий для проникновения в него (характерно, что последний пример использования словосочетания войти в интернет в Национальном корпусе русского языка относится к 2009 году).

Главная тенденция, свидетельствующая о том, что интернет-пространство - это абсолютно освоенный участок внеязыковой действительности, связана с появлением языковых единиц (в славянских языках - часто на базе новых заимствований из английского языка - стандартных или калькированных), референты которых изначально находятся именно в сети, - и сами эти единицы формируются в процессе интернет-коммуникации. Это, разумеется, неудивительно: объем взаимодействий в интернет-пространстве постоянно возрастает, регулярно возникают новые виртуальные объекты и явления - и так же регулярно формируются их названия (частично являющиеся

6 Здесь и далее приводятся примеры, обнаруженные при помощи поиска в Google. При цитировании сохраняется орфография и пунктуация оригинала. 
результатом целенаправленного корпоративного словотворчества, частично - стихийного коллективного). Упомянутые языковые средства в первую очередь связаны с пространством социальных сетей и микроблогов, ср. рус. nостить 'размещать запись в социальной сети или блоге' (и его дериваты запостить, перепостить), лайк' 'одобрение сообщения (текста, изображения, видео и т. п.) в социальных сетях или на любом сайте с помощью специальной кнопки, имеющей то же название' (Krongauz 196) и образованные от него глаголы лайкать и лайкнуть, первый из которых стал производящей основой для других приставочных глаголов, фолловить 'быть подписанным на обновления статусов какого-либо пользователя в сети', отписаться 'перестать быть подписанным на обновления статусов какого-либо пользователя в сети', польск. odlubic' 'отменить положительную реакцию на текст, изображение, профиль в соцсети и пр. при помощи повторного нажатия кнопки лайк': Jak odlubić wszystkie strony na Facebooku; Już was odlubiłam, skoro nie można do was napisać wiadomości prywatnej dotyczacej problemu z telefonem.

Уже здесь мы сталкиваемся с любопытным, но, если задуматься, вполне логичным и ожидаемым явлением, которое заключается в том, что, скажем, слово лайк, рожденное Интернетом и органично в нем существующее, начинает встречаться в контекстах вроде следующего: Лайк мужику. Если б не он, то сгорело бы полдома (комментарий на городском портале к статье о предотвращении пожара). Речь, очевидным образом, не идет о нажатии специальной кнопки в соцсети - пользователь выражает свое восхищение поступком героя статьи, совершенным в реальном мире.

Еще более ярко эту тенденцию демонстрируют русский глагол хейmumь и его польский эквивалент hejtować, исходно представляющие собой результаты адаптации английской глагольной основы к флективным системам славянских языков. Английское hate не употребляется в Интернете в принципиально новом значении - оно просто используется применительно к новому пространству. В славянских языках, в свою очередь, у заимствований $x e u ̈ m / h e j t$ и образованных от них глаголов специализированная функция - исходно они описывают особенности вербального взаимодействия именно в сети, ср.:

7 Подчеркнем, что в языке - источнике заимствования указанное значение слова like является, разумеется, результатом семантического развития глагола, исходно связанного с невиртуальным пространством; в русском языке, однако, это заимствование и его дериваты сразу стали употребляться применительно к интернет-пространству.

8 Отметим, что данная лексема семантически не связана с отписаться в значении 'написать формальный ответ, отделаться отпиской’. Названные единицы, как кажется, вполне возможно назвать омонимами. 
Новый клип певицы из Новосибирска стали хейтить в YouTube.

Я сегодня как раз об этом думала. Как же плохо человеку, который спецом подписывается, чтобы хейтить.

[...] a ludzie mnie za to zaczęli hejtować na Twitterze żebym przepraszała i musiałam aż nick zmienić Ahhaha.

Подчеркнем, что перед нами не просто результат искусственной адаптации английского слова к славянской словообразовательной системе, появившийся в языке как следствие моды на заимствования: ни хейтить, ни hejtować в этих контекстах невозможно заменить на ненавидеть/nienawidzić. Ненавидеть можно молча, тихо, скрыто - хейтить, не воплощая свою ненависть вербально, невозможно. Довольно быстро, однако, эти глаголы, исходно обозначающие ярко выраженную негативную реакцию, размещенную на сетевых площадках, то есть связанные с виртуальной реальностью, начинают употребляться для описания чувств и реакций в реальности невиртуальной:

[...] никогда не думала что буду хейтить спряжения глаголов.

Меня вынудили хейтить власть.

Хватить хейтить Кононова! Провал „Спартака” - не его вина [...]. Болельщики „Спартака" в своем стиле - проводили Олега Кононова в отставку омерзительными чантами, а сейчас на радостях готовы пускать фейерверки возле „Открытие Арены”.

[...] было так классно целых десять дней не хейтить себя.

[...] итак я легла спать с макияжем как скоро моя кожа начнет хейтить меня.

Za każdym człowiekiem sukcesu ciągnie się sznur hejterów, także im więcej będziecie hejtować reformę Ziobry tym lepsza ona będzie.

Hejtuje mojego brata, za to, że nie wykupił kanału history i wikingów obejrzę dopiero w weekend meh.

Итак, если вернуться к терминам теории концептуальной метафоры, то можно сказать, что в этом случае область-источник и область-цель до известной степени „поменялись местами”. Теперь виртуальное пространство предоставляет нам материал для осмысления действительности, лежащей за пределами Интернета. Можно, впрочем, описать имеющую место ситуацию и по-другому, как это делает Сандра Гриффенштерн: „One can argue that the Internet no longer is a separate world but part of everyday life (Можно предположить, что Интернет больше не отдельный мир, но часть повседневной жизни)" (Greiffenstern 161). Какое бы решение мы ни приняли, очевидно, что языковые единицы, называющие объекты, явления и процессы в Интернете, 
- это подсистема, которая практически в лабораторном режиме, под увеличительным стеклом демонстрирует нам закономерности семантической деривации, актуальные для естественного языка.

\section{Библиография}

Boryś, Wiesław. Słownik etymologiczny języka polskiego. Kraków, Wydawnictwo Literackie, 2005. Dubisz, Stanisław, red. Uniwersalny słownik języka polskiego [edycja CD-ROM, wersja 1.0]. Warszawa, Wydawnictwo Naukowe PWN, 2004.

Dytman-Stasieńko, Agnieszka, Jan Stasieńko. „WWW - Sieć metafor, metafory Sieci i studia nad Siecią". $W W W w$ sieci metafor: strona internetowa jako przedmiot badań naukowych. Red. Agnieszka Dytman-Stasieńko, Jan Stasieńko. Wrocław, Wydawnictwo Naukowe Dolnośląskiej Szkoły Wyższej, 2008, s. 9-20.

Evgen'eva, Anastasiâ P., red. Slovar'russkogo âzyka: w 4-ch t. Moskva, Russkij âzyk-Poligrafresursy, 1999.

Greiffenstern, Sandra. The influence of computers, the Internet and computer-mediated communication on everyday English. Berlin, Logos Verlag Berlin GmbH, 2010.

Krongauz, Maksim A., red. Slovar' âzyka interneta.ru. Moskva, AST-PRESS KNIGA, 2016.

Lakoff, George, Mark Johnson. Metaphors we live by. Chicago, University of Chicago Press, 2003. The Merriam-Webster Dictionary. Merriam-Webster, Inc., 2004.

Nacional'nyj korpus russkogo âzyka. Web. 20.12.2021. https://ruscorpora.ru/new/.

Norman, Boris Û. Teoriâ âzyka. Vvodnyj kurs. Moskva, Flinta, 2003.

Pinker, Steven. The stuff of thought: Language as a window into human nature. New York, Viking Press, 2007.

Slovar'russkogo âzyka XI-XVII vv. Vyp. 28: Stariček - Sulebnyj. Moskva, Nauka, 2008.

Tokar, Alexander. Metaphors of the Web 2.0: With special emphasis on social networks and folksonomies. Frankfurt am Main, Peter Lang, 2009.

Tolkovyj slovar' russkogo âzyka konca XX veka. Azykovye izmeneniâ. Red. Galina Nikolaevna Sklârevskaâ. Sankt Petersburg, ILI RAN, Izd-vo, 1998. 